\title{
Computer Aided Design to support fabrication of wrist splints using 3D printing: A feasibility study
}

Short title: Software design for 3D printed splints

\section{Authors:}

Main Correspondence: Dr Abby M. Paterson, Loughborough Design School, Loughborough University, Leicestershire, LE11 3TU. Email: A.M.Paterson@lboro.ac.uk

Ella Donnison, Pulvertaft Hand Unit, Royal Derby Hospital, Derby. DE22 3NE. Email:

Ella.Donnison@nhs.net

Dr Richard J. Bibb. Loughborough Design School, Loughborough University, Leicestershire, LE11

3TU. Email: R.J.Bibb@lboro.ac.uk

Dr R. Ian Campbell. Loughborough Design School, Loughborough University, Leicestershire, LE11

3TU. Email: R.I.Campbell@lboro.ac.uk

Acknowledgements: Many thanks to Lucia Ramsay of the University of Ulster for her support throughout, as well as all of the participants who kindly contributed to the investigation. Further thanks to; Dr Dominic Eggbeer and Sean Peel at PDR, Cardiff, Dr Candice Majewski at the University of Sheffield, Nigel Bunt and Sarah Drage of HK 3D Printing, and Phil Dixon at Loughborough University, for building physical proof-of-concept splint prototypes. Final thanks to Loughborough University for funding this research. 


\section{Introduction}

Patient compliance is a clear concern amongst practitioners such as occupational therapists (OT) and physiotherapists (PT) when prescribing splints. Wrist immobilisation splints are reportedly the most commonly prescribed wrist splints, ${ }^{1}$ and can be prescribed for a range of conditions including rheumatoid arthritis (RA) and carpal tunnel syndrome (CTS). Unfortunately, patient compliance/adherence can be affected for the following reasons;

- Difficulties keeping splints clean and dry ${ }^{2}$

- Induced perspiration, ${ }^{2,3}$ subsequently leading to odour issues ${ }^{4}$

- Poor aesthetics $^{2}$

- Fasteners (e.g. Velcro straps) which may initially be difficult to fix, adjust, remove and replace. ${ }^{2}$ Velcro straps (if used), for example, can also adhere to fabrics, ${ }^{2}$ subsequently causing damage to garments and upholstery

- Discomfort. Poorly fitted splints can cause paraesthesia and pressure points, ${ }^{2}$ e.g. over the ulnar styloid. ${ }^{3,5}$ Effects of incorrect fit can also result in friction ${ }^{6}$

- Limited function and compromised performance whilst performing everyday activities, such as washing dishes and dressing ones-self. ${ }^{4}$ For example, grip capabilities may be restricted due to the shape of the splint impacting within the palmar grasp, ${ }^{2}$ as well as reduced sensory information in the palm ${ }^{2}$

- Difficulty putting on or removing splints due to fastener types or the shape of the splint ${ }^{5}$

- Weight implications affecting proximal joints ${ }^{3}$

- Accommodating fluctuating oedema ${ }^{3}$ 
Furthermore, one could assume that the inclusion of cumbersome features such as folds, rolls, flares and additional padding based within the palmar region can affect grasp capacity.

Given the due care, attention and, consequently, time given by therapists to ensure that splints suit the needs of their patient to the best of their ability, the literature suggesting compromised compliance fuelled the researchers to explore alternative design and manufacturing opportunities which could be used by splinting practitioners. Therefore, an alternative approach is proposed by using Additive Manufacturing (AM).

Commonly referred to as $3 D$ printing, AM is the process of manufacturing a virtual $3 D$

representation of an object into a physical object layer by layer. ${ }^{7}$ AM offers many benefits, including functional, ergonomic, user-fit and aesthetic improvements which, collectively, can contribute to an improved emotional response to a personalised item. ${ }^{8}$ Since AM processes build an object layer by layer, the user can create almost any geometry, regardless of complexity, resulting in almost complete design freedom without incurring any extra cost. ${ }^{9}$ Material jetting AM processes are comparable to typical desktop paper-based inkjet printers found in many households today which use ink cartridges. However, rather than depositing a single layer of ink, multiple layers of material resin are deposited to build an object over time, and cured/fixed using an ultraviolet (UV) light (Figure 1). There are, however, many other AM systems available with different processes and materials. A general description of other AM processes and medical applications can be found in Bibb ${ }^{10}$ and Hopkinson and Dickens. ${ }^{11}$ 


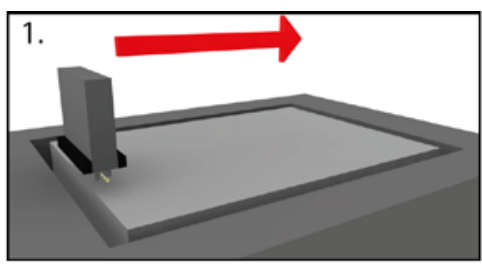

Print head moves from left to right to deposit resin material (build and support).

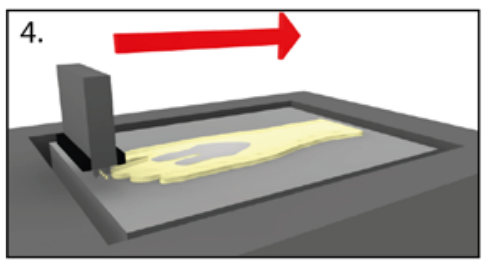

Step 1 is repeated.

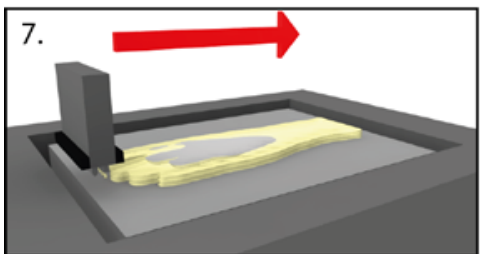

Previous steps are repeated..

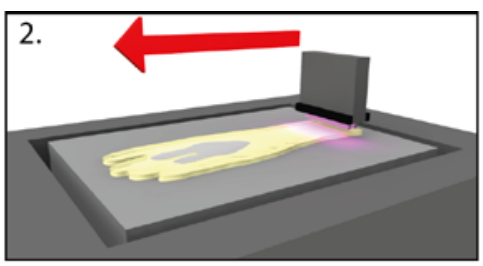

The print head returns from right to left, and cures the resin with a UV lamp.

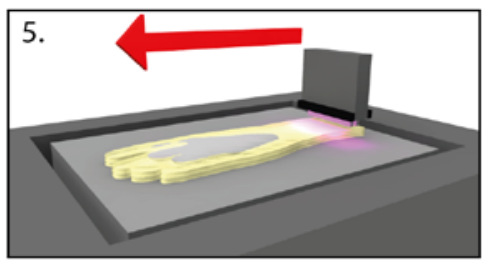

Step 2 is repeated.

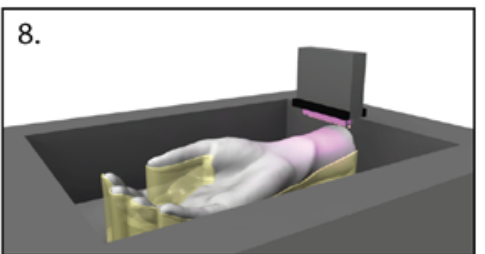

..until the entire object is built.

Figure 1: Material Jetting process

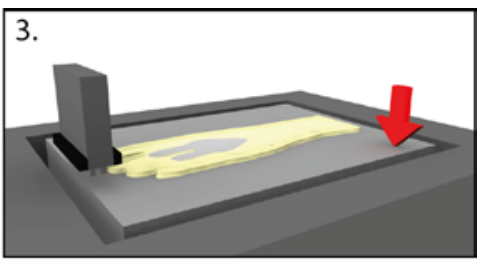

The build platform moves down in order to accommodate further layers of material.

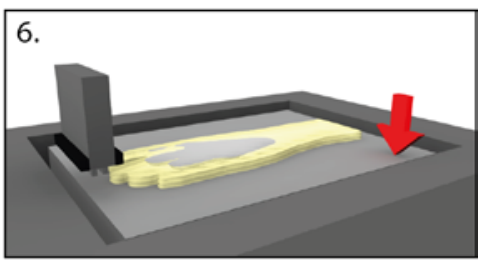

Step 3 is repeated.

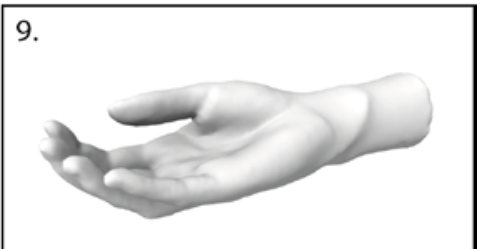

Support material is removed by hand and the final object is ready.

One particular area where AM excels is the fabrication of bespoke-fitting items, and is already an established method of producing custom-made hearing aids. ${ }^{12}$ Other applications of AM in medicine include maxillofacial prostheses, ${ }^{13}$ surgical guides ${ }^{14,15}$ and surgical training apparatus for pre-operative planning, ${ }^{15}$ to name a few.

The concept of using AM for making wrist splints is not new. A particular material jetting system called the Objet Connex was used to create Carpal Skin; a prototype splint which integrated flexible rubber-like materials alongside rigid materials for personalised movement in certain directions. ${ }^{16}$ The aim was a potential treatment method for CTS, although there is no medical evidence to date 
as to whether such an approach is effective. Paterson et al. ${ }^{17}$ developed a range of AM prototypes using different AM processes including single material and multiple material splints, to demonstrate the capabilities of AM for custom splint fabrication. However, perhaps the most publicised example of AM for upper extremity immobilisation was the Cortex splint by Evill, ${ }^{18}$ aimed specifically at trauma patients, offering improved aesthetics and ventilation. A similar approach has also been proposed by Carmichael, ${ }^{19}$ Karasahin, ${ }^{20}$ and Fraunhofer IPA. ${ }^{21,22}$ However, these approaches demonstrated limited opportunities to capture practitioners' preferences on fit and performance, nor did they propose an approach to integrate alternative lattice shapes to suit individual patient preferences in styles.

Despite these efforts in applying AM splint fabrication, a suitable 3D virtual representation of the desired object must first be captured and/or designed in a virtual environment. For example, in order to create a custom-fitted item such as a maxillofacial prosthesis, ${ }^{23}$ one must first capture a digital 3D representation the patient's unique scan data using a suitable data capture method, e.g. Computed Tomography (CT). The captured digital data is then used to inform the design of the prosthesis to fit the patient and their needs; to do this, 3D Computer Aided Design (CAD) software is used. Using a similar strategy, it is anticipated that there are three key stages to the Digitised Splinting Process (DSP), as depicted in the workflow diagram proposed in Figure 2.

Key stage i. data acquisition of the patient's upper extremity skin surface topography to give a 3D virtual representation (e.g. using 3D laser scanning)

Key stage ii. manipulation of the captured 3D virtual scan data in a virtual environment to create a suitable splint in 3D CAD;

Key stage iii. manufacture of the finalised manipulated data, using AM. 


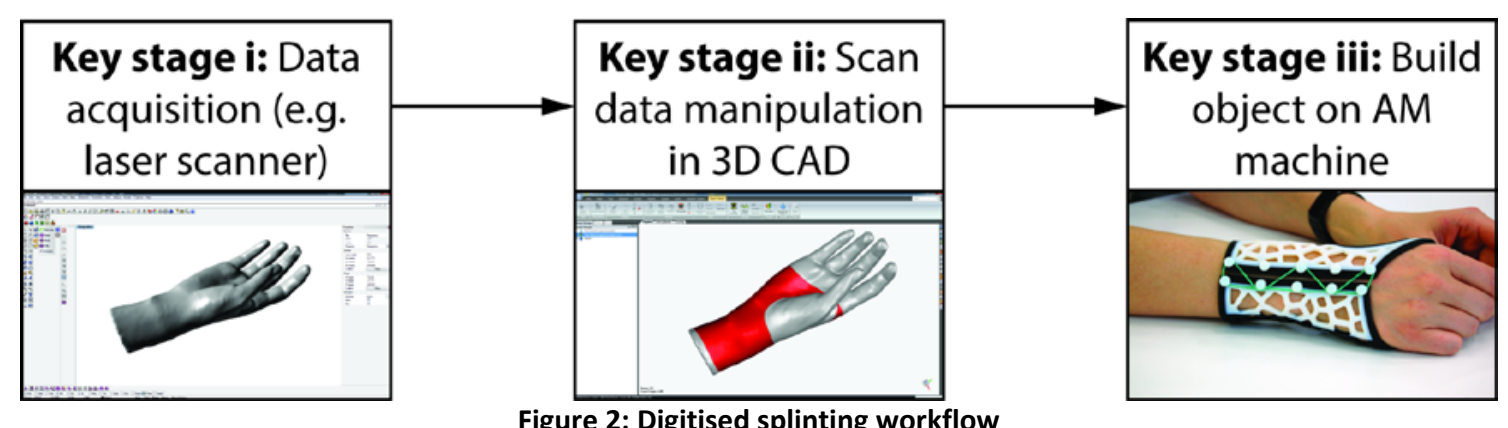

Figure 2: Digitised splinting workflow

Supposing that a suitable data capture method has already been identified for the capture of a patient's skin surface or 'topography', the data would need adjusting in 3D CAD software to create a desired splint design. Fried ${ }^{24}$ proposed an automated system which would require the transfer of therapists' responsibilities and clinical decision-making to a more constrained approach; the needs of patients would be communicated to a CAD expert at a CAD consultancy or AM factory (or 'service bureau'), for example, who would then design the splint prior to fabrication via AM. However, the abundant weakness of this approach was the level of disregard for therapists' skills, knowledge and expertise in the field, and failing to acknowledge their place in the healthcare pathway to deliver quality splints for patients on an individual basis. Such an approach would inevitably result in data lost in translation, and susceptibility to error, resulting in increased cost and frustration to patients and therapists. Furthermore, the automated approach proposed by Fried $^{24}$ would remove the skills and expertise from the splint design and fabrication process delivered by therapist, with potential redundancies as a result. In contrast to this, the authors of this study chose to explore alternative options that would require and subsequently maintain the skills and expertise of therapists whilst potentially offering a wider skillset to them through CAD and AM. Therefore, the authors chose to explore the opportunity for splinting practitioners to use 
3D CAD. However, Rogers et $a l .{ }^{25}$ highlight concerns relating to the lack of specialised software tools for health practitioners within the field to design artefacts for AM, often resorting to outsourcing or having to invest significant cost in time and training in order to use mainstream engineering CAD software. Subsequently, Rogers et al. $^{25}$ suggested that suitable specialised software tools should be developed which would allow health practitioners to capture their intended splint design quickly and with minimal training. This view is supported by Pallari et al., ${ }^{26}$ who also established a refined CAD process for lower limb orthoses in support of AM. Prior to this study there was no specialised CAD software available for upper extremity splinting with a splinting sequence sympathetic to that of traditional splinting to ease the transition for splinting practitioners.

\section{Proposed intervention, aim and objectives}

In response to the needs and concerns described previously, the aim of the investigation was to develop a specialised splinting software approach to allow therapists to design splints in a virtual environment, based on patient specific scan data. The proposed 3D CAD approach had to include the means to integrate typical features incorporated in custom-made splints, such as flared edges, cavities over prominences susceptible to pressure (i.e. bony prominences or rheumatoid nodules), and the inclusion of padded lining. Conformability was also included since choosing the conformability of Low Temperature Thermoplastics (LTT) was considered a valuable decisionmaking process in splint fabrication.

Furthermore, the researchers chose to explore the integration of a number of other beneficial innovative features, made possible using AM technologies. These features included; 
1. Aesthetic lattice integration, which would not only look visually appealing to suit each patient's preference/styles, but could also improve skin ventilation and reduce weight (as proposed by Bibb, ${ }^{27}$ Figure 3).

2.
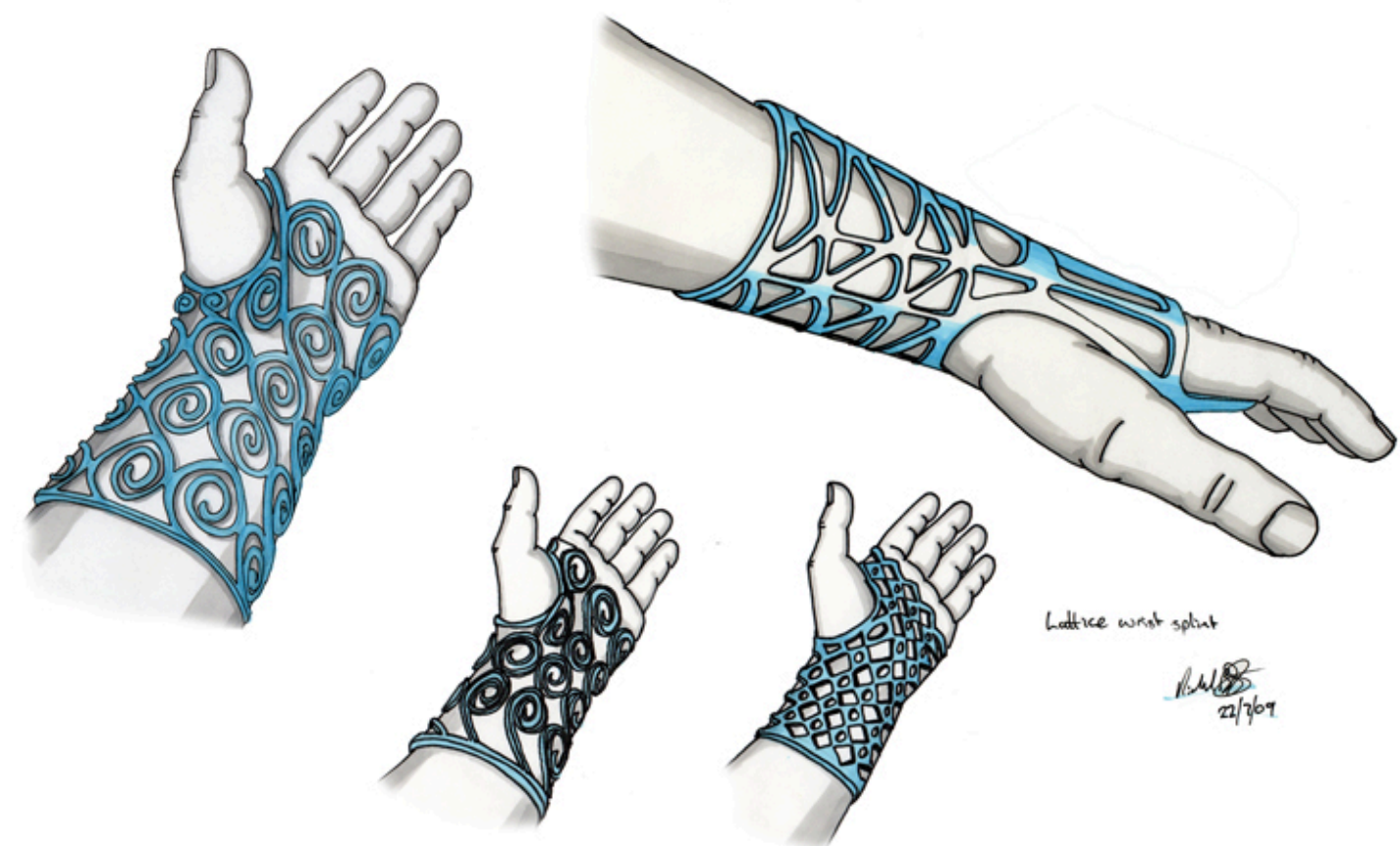

Ladtrce wrost splint

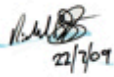

Figure 3: Splinting proposal concepts, delivered through additive manufacturing technologies. ${ }^{28}$ Image courtesy of

\section{Bocking of CRDM}

3. Multiple-material feature integration. In contrast to work by Oxman, ${ }^{16}$ the investigators sought to integrate multiple materials to suit the practitioner's preference on location to deliver other forms of novel functionality, such as;

a. Expanding regions located over areas susceptible to swelling fluctuation, whilst providing adequate pressure to avoid oedema pooling 
b. The integration of elastomer hinges, which could be subtle in appearance whilst making the splint easier to put on and take off

c. Cushioning features over regions prone to pressure, e.g. pisiform and ulnar styloid. In contrast to traditional splinting where a localised cavity may be required to enable pronation and supination, an elastomer region could expand and contract to suit the motion of the patient, without affecting the topography of the splint. In response to these requirements, the following objectives were established to help structure the investigation;

Objective 1. Identify suitable tools/strategies in 3D CAD, to reproduce particular features and essential characteristics for wrist immobilisation splints

Objective 2. Identify suitable tools/strategies in 3D CAD to incorporate lattice structures into splints

Objective 3. Identify suitable tools/strategies in 3D CAD to incorporate multiple materials into splints

Objective 4. Refine final tools/strategies into a logical sequence (workflow), replicating the traditional fabrication process

Objective 5. Evaluate the workflow and inform future improvement and research.

\section{Method}

Key splint characteristics of the traditional splinting process such as conformability, flaring and splint thickness were replicated in mainstream 3D CAD software such as Geomagic Studio (Geomagic Solutions, Raleigh, NC, USA), to demonstrate feasibility. New features (e.g. lattice and multimaterial integration) were also explored using different CAD software, such as McNeel 
Rhinoceros (Robert McNeel \& Associates, Seattle, WA, USA). Several strategies emerged, which were refined into a logical order; a workflow. The order was primarily dictated by splinting processes described in splinting education literature. ${ }^{29-31}$ The order was also defined by bestpractice CAD modelling strategies for each feature requirement, which are described in detail by Paterson. $^{32}$

The refined workflow is displayed in Figure 4. It is important to note that the model was designed to enable traversal operation, meaning that the path through the workflow was not necessarily linear, unlike traditional splinting where the further one progresses through the fabrication process, the more difficult and time consuming it may be to make both major and minor adjustments. The digitised workflow enabled users to move back and forth between different stages in the workflow, or bypass certain steps all together. The intent of this was to enable design freedom when designing splints in a virtual environment, and not constrain the user to an otherwise limited process. This offers a potentially radical change in the design and manufacture process as many designs can be attempted and changed rapidly at little to no cost before proceeding to manufacture. 


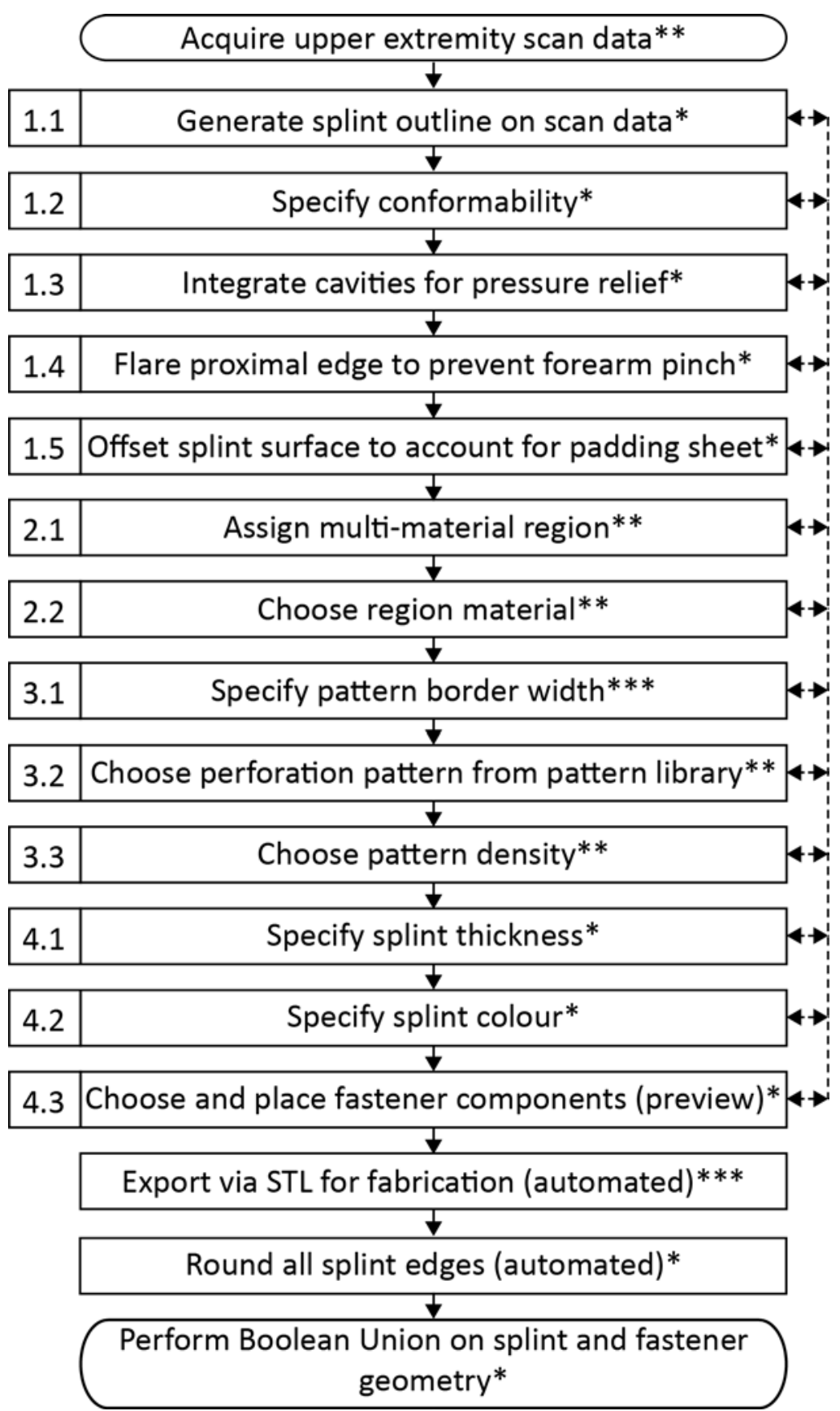

Figure 4: Refined digitisation sequence workflow ${ }^{32}$ 
The workflow was then translated into a software prototype, designed and programmed in Microsoft Access 2010 (Microsoft Corporation, Redmond, WA, USA). The purpose of the prototype was to depict a functional piece of software to assist in the evaluation process (Objective 5). The prototype computer screen interface is shown in Figure 5; the left of the interface featured controls for the user to interact with, whilst the right of the screen interface featured a viewport, which provided visual feedback to the user. The software prototype also featured categorisation tabs at the top of the window, which allowed users to navigate to a particular set of tools, ranging from 'Personal details', 'Splint pattern design', 'Multi-material integration', 'Pattern integration' and 'Final Settings and Manufacture'. 'Pattern Integration', for example, featured a perforation shape library, which allowed users to browse different perforation shapes. The intent of this tool was to demonstrate that co-design could be enabled even further than the extent in current splinting practices, by allowing the patient to become involved in choosing the appearance of their splint in a bid to improve compliance.

The benefit of this approach was that the prototype was interactive and permitted participants to explore tools and view effects of their decision-making in the viewport of the computer screen interface. For example, Figure 6 shows the effects of changing the perforation density slider control on the left of the window from 'low' to ' $h i g h$ '; the resulting image is shown in the viewport to give visual feedback. 


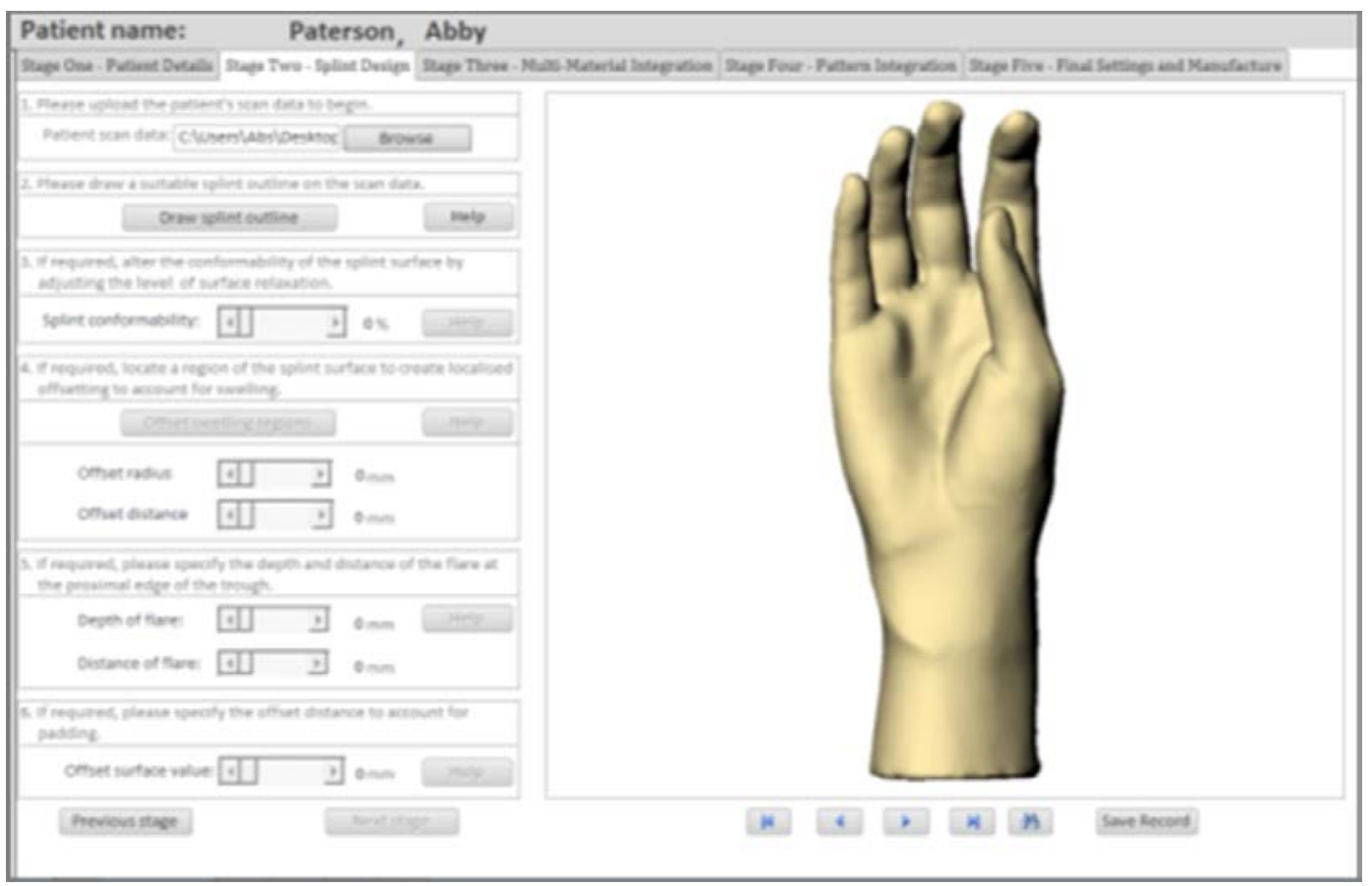

Figure 5: Software prototype interface 32
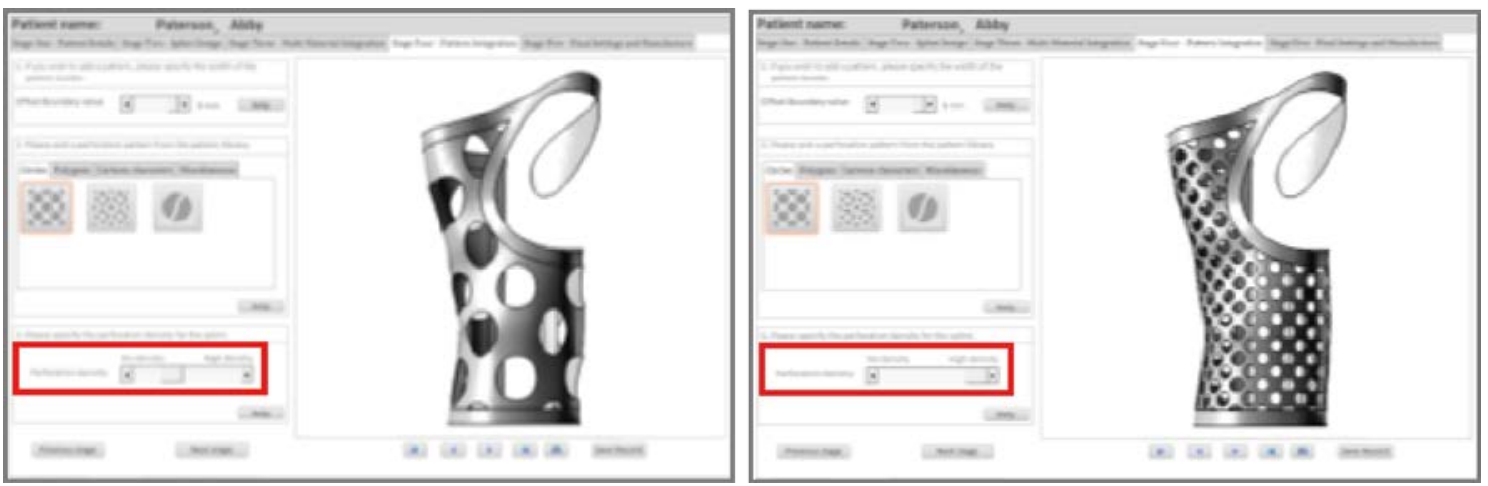

Figure 6: Perforation density control (left image = low density, right image $=$ high density) 32

The prototype also demonstrated how the user could incorporate multiple material regions into the splint, as described by Paterson et al. ${ }^{33}$ 
In order to evaluate the digitised splint design approach, a number of participants were required to evaluate the software tool. A snowball sampling strategy was used to gather practitioners with ranging demographics for the study. Participants ranged in geographic location across the United Kingdom and subsequently diversity in workplace, experience and qualifications.

Eight occupational therapists and two physiotherapists took part in the evaluation studies. Demographics of the participants are shown in Table 1. 
Table 1: interview cohort (PP = pilot participant; IP = Interview participant). Adapted from Paterson ${ }^{32}$

\begin{tabular}{|c|c|c|c|c|c|}
\hline $\begin{array}{l}\text { Participant } \\
\text { number }\end{array}$ & Professional status & $\begin{array}{l}\text { Location of } \\
\text { primary } \\
\text { workplace }\end{array}$ & $\begin{array}{l}\text { Number of } \\
\text { years } \\
\text { splinting } \\
\text { experience }\end{array}$ & $\begin{array}{l}\text { Computer } \\
\text { usage }\end{array}$ & $\begin{array}{l}\text { Previous CAD } \\
\text { experience? }\end{array}$ \\
\hline PP310 & $\begin{array}{l}\text { Occupational } \\
\text { therapist } \\
\text { Accredited Hand } \\
\text { therapist }\end{array}$ & England & Over 10 years & Daily & No \\
\hline IP200 & $\begin{array}{l}\text { Accredited hand } \\
\text { therapist (BAHT) }\end{array}$ & $\begin{array}{l}\text { Northern } \\
\text { Ireland }\end{array}$ & Over 10 years & Daily & No \\
\hline IP312 & $\begin{array}{l}\text { Occupational } \\
\text { therapist advanced } \\
\text { (band 7) } \\
\text { Level II hand therapist }\end{array}$ & England & Over 10 years & Daily & No \\
\hline IP314 & $\begin{array}{l}\text { Occupational } \\
\text { therapist advanced } \\
\text { (band 7) }\end{array}$ & England & Over 10 years & Daily & No \\
\hline IP316 & $\begin{array}{l}\text { Occupational } \\
\text { therapist advanced } \\
\text { (band 7) }\end{array}$ & England & Over 10 years & Daily & No \\
\hline IP318 & $\begin{array}{l}\text { Physiotherapist } \\
\text { specialist (band 6) } \\
\text { Level II hand therapist }\end{array}$ & England & $4-6$ years & Daily & No \\
\hline IP400 & $\begin{array}{l}\text { Occupational } \\
\text { therapist advanced } \\
\text { (band 7) }\end{array}$ & Scotland & $4-6$ years & Daily & No \\
\hline IP412 & $\begin{array}{l}\text { Occupational } \\
\text { therapist advanced } \\
\text { (band 7) } \\
\text { Level II hand therapist }\end{array}$ & England & 4-6 years & Daily & No \\
\hline IP414 & $\begin{array}{l}\text { Physiotherapist } \\
\text { specialist (band 7) } \\
\text { Level III hand } \\
\text { therapist }\end{array}$ & London & $1-3$ years & Daily & No \\
\hline IP416 & $\begin{array}{l}\text { Occupational } \\
\text { therapist specialist } \\
\text { (band 6) }\end{array}$ & $\begin{array}{l}\text { Northern } \\
\text { Ireland }\end{array}$ & 4-6 years & Daily & No \\
\hline
\end{tabular}


The evaluation sessions featured four stages;

i. a briefing into the aim and objectives of the investigation

ii. a demonstration of the software prototype

iii. user trials of the software prototype

iv. a semi-structured interview.

A pilot study was initially completed to ensure aspects of the evaluation sessions were performed as intended, and to identify areas for improvement. For the final sessions after the pilot study, all but one session was conducted on a one-to-one basis, involving the interviewer and the participant, although a chaperone was also present to comply with University Ethics requirements. The ninth session involved two participants, as they were colleagues at the same hospital. Participants were given an information sheet prior to the evaluation session, and asked to complete an Informed Consent form. Participants were assured anonymity, and were assigned a number for future reference (e.g. 318).

In addition to the software prototype, several physical splint prototypes were used to demonstrate the proposed output of the DSP throughout the evaluation sessions. 


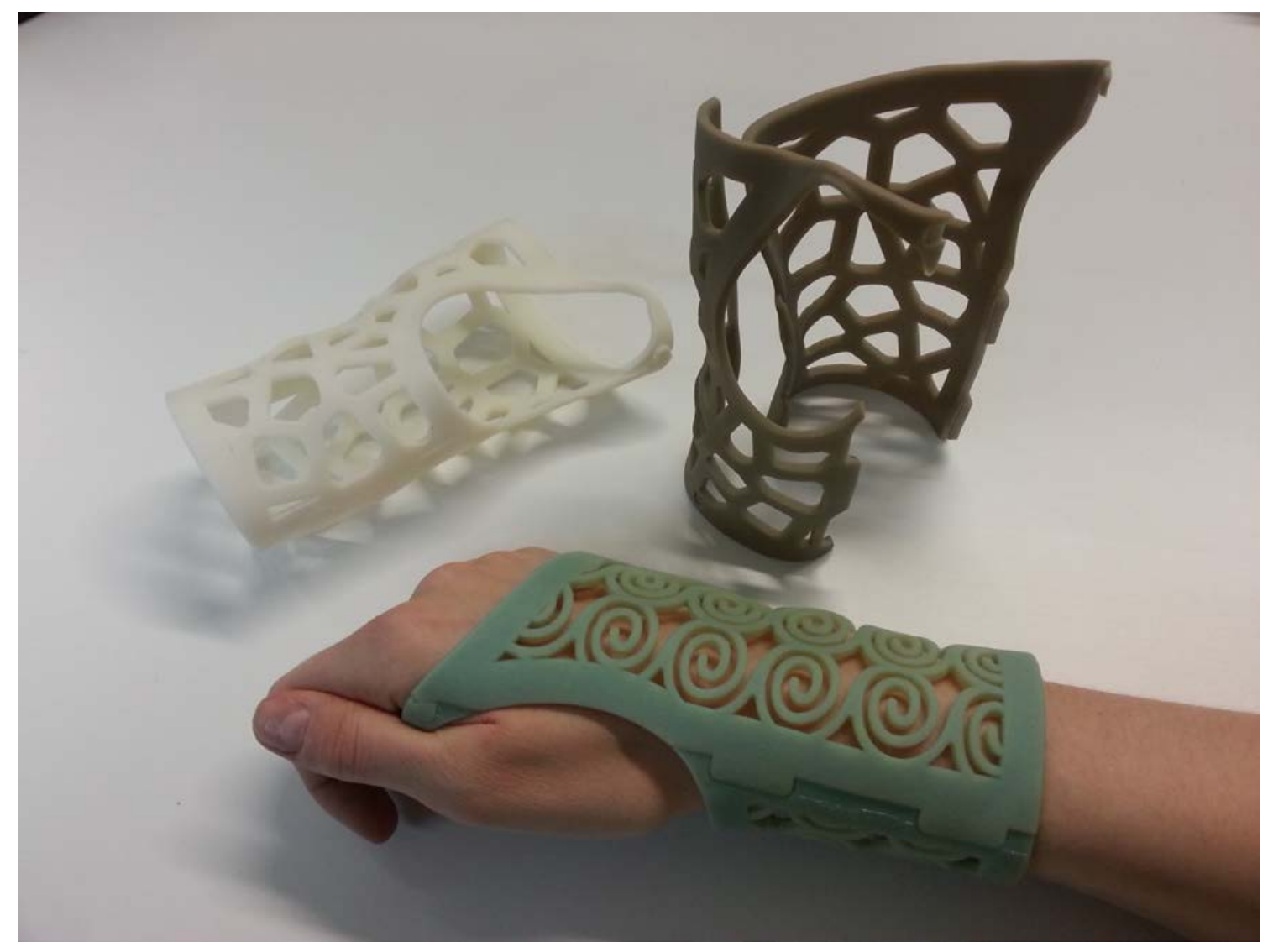

Figure 7: Proof-of-concept AM wrist splint prototypes

Questions during the semi-structured interview related to perceived ease of use of the software prototype, as well as highlighting discrepancies regarding tools, perceived outcome of splint designs, concerns over the workflow whilst using the prototype, and areas for future development. Audio recordings were made throughout the sessions, which were then transcribed in Microsoft Word (Microsoft Corporation, Redmond, WA, USA). Transcriptions were coded within NVivo (QSR International Ply Ltd, Doncaster, Australia) to establish trends in opinions. 


\section{Results}

Participants welcomed the digitised intervention for splinting, and subsequently were willing to evaluate the proposed 3D CAD software prototype. Due to the creative nature of splinting, participants were keen to suggest new, innovative design features in addition to those proposed, which demonstrated the engagement that participants had with the splinting process and an appreciation for beneficial change. Suggested additional design features included;

- Opportunities to incorporate multimaterial edges around splints for a softer interaction between the skin and the splint. Such a feature would potentially remove the need to roll edges of the splint, as well as more flexible support for the metacarpophalangeal (MCP) joints.

- The integration of engraved text and symbols into the splints as indicators or instructions as to how patients should put on/take off their splints, as well as patient identification information, dates, serial numbers, and care instructions (e.g. lists of suitable detergents and wash temperatures).

- The ability to specify or localise the integration of lattice structures into a splint; rather than having a lattice occur throughout the splint, one particular participant wanted to only allocate perforations to a small region (e.g. only the palmar region).

- Opportunities to produce 2D paper printouts of a patient's flattened splint template, which could be used to check the fit before manufacture. This suggests a similar quality check to traditional fabrication processes, which could be used to ensure the correct length of the forearm trough, for example. 
- Allowing the user to alter the ratio between the perforation lattice design and the material, particularly in areas that might require a more densely populated area (Figure 8).

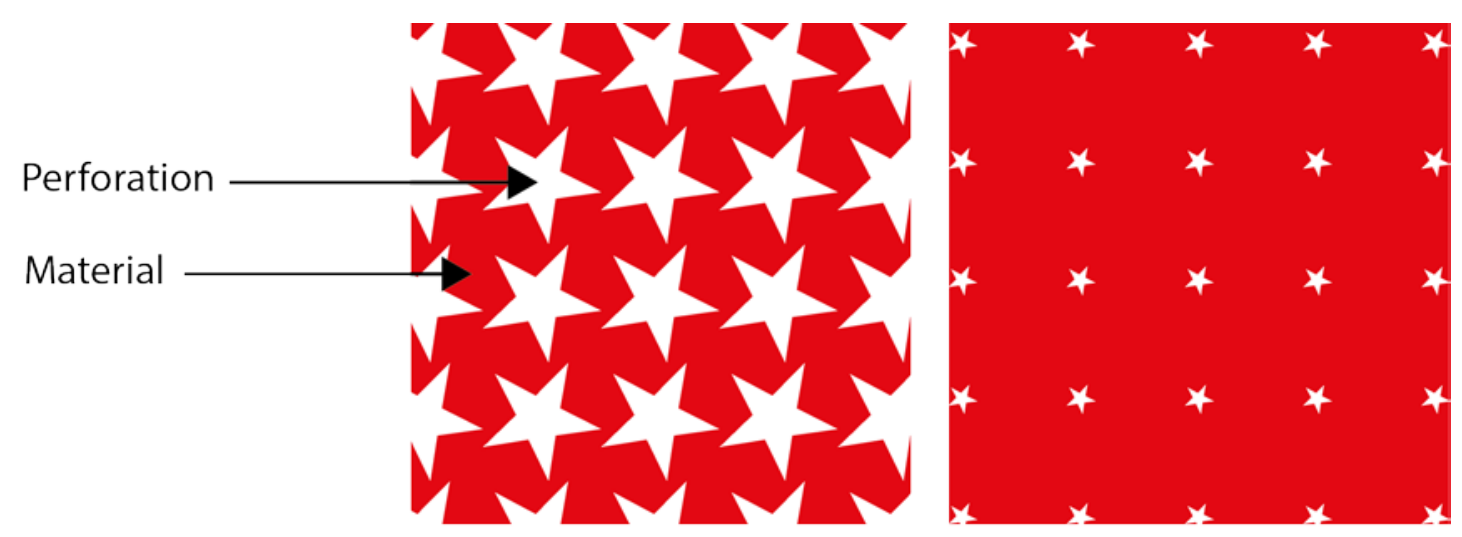

High perforation: low material Low perforation: high material

Figure 8: Perforation-to-material ratio alterations to potentially reduce swelling protrusion and increase strength

One participant was also interested in the potential for reduced human error compared to traditional splinting, whereby a splint may be made for the wrong wrist/forearm. This results in wasted materials, time, and therefore cost to the clinic and patient. However, the digitised approach would eliminate this error since only necessary patient scan data would be loaded and adjusted to suit. Furthermore, an additional participant was interested in using the software as a teaching aid, to hone their own skills as well as teaching students in OT and PT on how to make splints (e.g. identifying typical landmarks). The same participant was also interested in the relative ease in creating more complex splints which, depending on the level of experience, may be more challenging to fabricate than the standard wrist immobilisation splint. The participant attempted to 
model a thumb spica using the proposed approach by manipulating the scan data, with overall success;

"I find the thumb one of the most difficult areas to splint. To get good support; to get the thumb into a nice functional position, and then actually maintaining it in that position. To provide something that's really comfortable and conforms...this software might actually really help, because you've got splints out there that are good design but aren't always particularly comfortable. And to actually hold the hand rigidly in a functional position without causing discomfort, it's really difficult. And this might actually have the answer" (Participant 312).

In terms of the potential to improve the efficiency of the splinting process, participants described some of the compromises that may be made during traditional splinting such as sacrificed conformability as a result of needing a stronger LTT. As a result of the digitised process, each of these variables could be adjusted independently to suit, and the ability to move between different steps independently would also enable quick design adjustment.

The previous suggestions were considered deliverable through the use of 3D CAD, and therefore could be implemented into custom-made fully functional software. However, there were a number of other suggestions which currently would not be feasible when considering the current state-ofthe-art in AM, but is entirely plausible in future technological development. These ideas included;

- The integration of elastomer materials with suitable properties to treat burns victims, in order to apply consistent pressure.

- The integration of additional components for dynamic splinting (e.g. pulley systems) to reduce the size, weight and improve appearance. 
Therapists felt the intervention would be applicable for a wide range of individuals, from paediatrics to the elderly and from symptom management to prevention/protection against sports injuries, for example. Furthermore, the majority of participants concurred that the approach would be best suited for chronic conditions rather than short term acute ailments, due to expenditure. There were also concerns about the approach and areas for future work; two participants expressed concerns over swelling protruding through lattice perforations, suggesting potential damage to superficial soft tissue. One participant was also concerned that adherence would reach an alternate point where they could foresee difficulties in weaning their patients off their splints. Cost was also a significant factor, and voiced by the majority. For example the resin for the multimaterial Objet Connex system is considered one of the most expensive polymer resins on the AM market, costing approximately $£ 200$ per kilogram (excl. VAT) for the cheapest material. However, other AM processes and materials can be much cheaper. In order to assist in comparisons, Table 2 summarises the costings of four different AM processes with five different materials, sourced from three different AM service bureaus within the UK. The costings are based on the splint design which is being worn in Figure 7. The costs include additional elements of the service bureaus such as overheads as well as the material costs, but exclude VAT and postage fees. It should be noted that this is a limited selection of processes and materials; access and affordability of equipment and materials are changing rapidly so it is anticipated that these costings will reduce with time. It should also be noted that a very limited number of AM materials are currently biocompatible; some of the materials in Table 2 have not been registered as biocompatible and therefore have been used for proof-of-concept prototypes only and are not intended for functional use at this stage. In terms of equipment costs; hobbyist low-cost 3D printers can be purchased for 
approximately $£ 2000$, whilst industry standard machines can range from approximately $£ 30,000$ $£ 700,000$. The worn splint in Figure 7 for example was made on an Objet Connex 500 machine which cost approximately $£ 250,000$; although this may sound expensive, the equipment is capable of making highly accurate objects and can offer a range of materials and multimaterial build capabilities. 
Table 2: Splint costings relative to AM process and materials for the worn splint shown in Figure 7

\begin{tabular}{|c|c|c|c|}
\hline Process & Description of process & Material & $\begin{array}{l}\text { Cost (excl } \\
\text { VAT) }\end{array}$ \\
\hline $\begin{array}{l}\text { Material jetting } \\
\text { (specifically Objet } \\
\text { Connex system) }\end{array}$ & $\begin{array}{l}\text { Droplets of photopolymer resin } \\
\text { are deposited by printheads. The } \\
\text { droplets are then cured using an } \\
\text { ultraviolet light (consult Figure } 1 \\
\text { or www. Stratasys.com for more } \\
\text { information) }\end{array}$ & ABS-like & $£ 314-£ 505$ \\
\hline $\begin{array}{l}\text { Material jetting } \\
\text { (specifically Objet } \\
\text { Connex system) }\end{array}$ & $\begin{array}{l}\text { Droplets of photopolymer resin } \\
\text { are deposited by printheads. The } \\
\text { droplets are then cured using an } \\
\text { ultraviolet light (consult Figure } 1 \\
\text { or www. Stratasys.com for more } \\
\text { information) }\end{array}$ & $\begin{array}{l}\text { VeroWhitePlus } \\
\text { (Stratasys/Objet } \\
\text { branded } \\
\text { material) }\end{array}$ & $£ 298-375$ \\
\hline $\begin{array}{l}\text { Fused Deposition } \\
\text { Modelling (FDM) }\end{array}$ & $\begin{array}{l}\text { A polymer filament is passed } \\
\text { through a heated element and } \\
\text { fine nozzle to form a continuous } \\
\text { semi-liquid string, which is } \\
\text { extruded along a computer- } \\
\text { controlled path (consult } \\
\text { www.Stratasys.com for more } \\
\text { information) }\end{array}$ & ABS & $£ 280-£ 565$ \\
\hline Laser Sintering (LS) & $\begin{array}{l}\text { A powder-based process, where } \\
\text { thin layers of polymer powder are } \\
\text { rolled to form a thin layer; a laser } \\
\text { is then passed over the powder } \\
\text { in a specific path to 'sinter' the } \\
\text { particles together (consult } \\
\text { www.eos.info/en for more } \\
\text { information) }\end{array}$ & Nylon PA & $£ 114.00$ \\
\hline $\begin{array}{l}\text { Stereolithography } \\
\text { (SLA) }\end{array}$ & $\begin{array}{l}\text { A vat of photopolymer resin is } \\
\text { used; a build platform lowers in } \\
\text { the vat incrementally, and an } \\
\text { ultraviolet laser passes over the } \\
\text { platform in a predefined path to } \\
\text { cure the resin into a solid state } \\
\text { (consult www.3DSystems.com } \\
\text { for more information) }\end{array}$ & Standard epoxy & $£ 157.00$ \\
\hline
\end{tabular}




\section{Discussion}

As the results suggest, therapists were willing to not only use the software prototype, but also engaged with it to the point where they were requesting future functions to improve the approach further. Although the sample size was small and subsequently could not be used to form any generalisations or opinions of the overall population of practising splinting practitioners in the UK, the results demonstrated that there was sufficient interest to justify future research and development to form fully functional specialised software to support the DSP. To demonstrate the researchers' interest in pursuing future developments in this area, the authors carried through one of the participants' suggestions, to integrate multiple materials around the edges of the splint to offer softer edges for the potential patient (Figure 9). This removed the need to flare the proximal edge. 


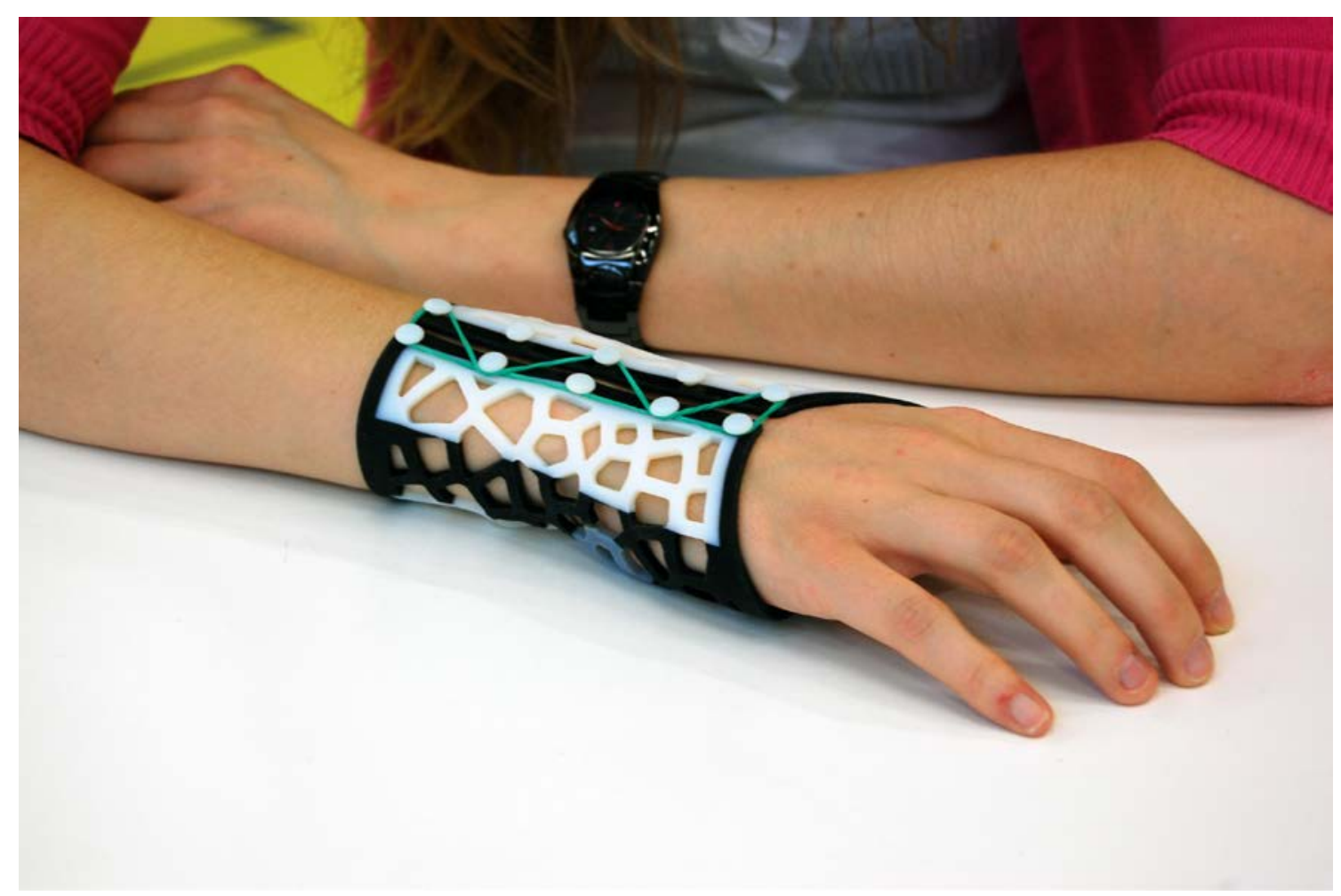

Figure 9: multimaterial splint

However, in order for the approach to become clinically feasible, future work on several areas must be performed. A number of participants were concerned about the best approach for capturing patient scan data, particularly if a particular posture is to be captured (e.g. 30 degrees hyperextension with 25 degrees ulnar deviation). Future research is required to establish whether rigging a patient's forearm would be required in this case, and the implications that this would have in generating valid data for manipulation in CAD, taking into account the likely deformation of soft tissue.

Material suitability would also be a demanding area to focus on. To date, there are a very limited number of AM materials that conform to recognised standards for skin irritation / toxicity (e.g. ISO 
10993), and they would still require clinical studies to assess suitability for mainstream treatment. Furthermore, the specialised software proposed in this paper must be created as fully functional by software programmers and engineers. A larger study would also be necessary to gather feedback from a larger practitioner cohort as a result.

Taking into consideration the costs for materials, machine maintenance and other additional running costs as well as skilled labour (both therapist time and technician time for machinery), the approach would require a thorough cost benefit analysis against current splinting practices. Although the approach may appear expensive when simply based on materials costs, AM is becoming more affordable as demand increases. Furthermore, several considerations may be accountable in favour of design for AM, such as;

- The ability to save splint design files which may be opened and reused at a later date. This approach would serve to help in providing spares, multiple splints for different activities and repeat prescriptions where patients may have lost, broken or soiled their splint and would require a duplicate.

- The ability to adjust a previously saved splint file to integrate alternative features (e.g. a different perforation pattern or additional fasteners), without having to redesign the entire splint and possibly without a patient appointment at clinic.

These points suggest opportunities to save therapist time which could subsequently free up appointment slots. Waiting times could be reduced, and patient satisfaction could therefore be increased. Overall, the digitised approach opens up many new and exciting opportunities in the field of occupational therapy and physiotherapy provided the limitations can be addressed in due course. 


\section{Funding}

This research received no specific grant from any funding agency in the public, commercial or notfor-profit sectors. Funding was received from Loughborough University in the form of a PhD studentship.

\section{Ethics and consent}

This investigation complied with Loughborough University's Ethical Advisory Committee requirements; participants were supplied with an information sheet and asked to sign an informed consent form prior to the start of their involvement to declare their willingness to take part.

Participants were assigned a unique alias to protect their identity throughout the investigation and subsequent documentation.

\section{Competing interests}

None declared. 


\section{References}

1. Stern EB. Wrist Extensor Orthoses: Dexterity and Grip Strength Across Four Styles. The American Journal of Occupational Therapy 1991; 45(1):42-49.

2. Veehof MM, Taal E, Willems MJ and van de Laar MAFJ. Determinants of the use of wrist working splints in rheumatoid arthritis. Arthritis Care \& Research 2008; 59(4):531-536.

3. Melvin JL. Rheumatic disease: Occupational therapy and rehabilitation. Second ed. F. A. Davis Company; 1982.

4. Sandford F, Barlow N and Lewis J. A Study to Examine Patient Adherence to Wearing 24-Hour Forearm Thermoplastic Splints after Tendon Repairs. Journal of Hand Therapy 2008; 21(1):4452.

5. Melvin JL. Rheumatic disease in the adult and child: Occupational therapy and rehabilitation. Third ed. Philadelphia: F.A. Davis Co.; 1989.

6. Fess EE and Philips CA. Hand Splinting: Principles and Methods. Second ed. St Louis: Mosby; 1987.

7. American Society for Testing and Materials International. ASTM F2792 - 12a. Standard Terminology for Additive Manufacturing Technologies. West Conshohocken, PA.: ASTM; 2012.

8. Campbell RI. Customer Input and Satisfaction. In: Hopkinson N, Hague JM, Dickens PM (eds.) Rapid Manufacturing: An Industrial Revolution for the Digital Age Chichester: John Wiley \& Sons, Ltd.; 2006. p. 19-38.

9. Hague RJM, Campbell RI and Dickens P,M. Implications on design of rapid manufacturing. Proceedings of the Institution of Mechanical Engineers, Part C: Journal of Mechanical Engineering Science 2003; 217(1):25-30.

10. Bibb R. Medical Modelling: The Application of Advanced Design and Development Techniques in Medicine. Cambridge: Woodhead Publishing; 2006.

11. Hopkinson N and Dickens PM. Rapid Manufacturing: An Industrial Revolution for the Digital Age. West Sussex: John Wiley \& Sons, Ltd.; 2006.

12. Masters $M$, Velde T, McBagonluri F. Rapid Manufacturing in the Hearing Industry. In: Hopkinson N, Hague RJM, Dickens PM (eds.) Rapid Manufacturing: An Industrial Revolution for the Digital Age Chichester: John Wiley \& Sons, Ltd.; 2006. p. 195-210. 
13. Chandra A, Watson J, Rowson J, Holland J, Harris R and Williams D. Application of rapid manufacturing techniques in support of maxillofacial treatment: evidence of the requirements of clinical applications. Proc.Inst.Mech.Eng.Pt.B: J.Eng.Manuf. 2005; 219(6):469-475.

14. Bibb R, Eggbeer D, Evans $P$, Bocca A and Sugar A. Rapid manufacture of custom-fitting surgical guides. Rapid Prototyping Journal 2009; 15(5):346-354.

15. Harris R, Savalani M. Medical Applications. In: Hopkinson N, Hague RJM, Dickens PM (eds.) Rapid Manufacturing: An Industrial Revolution for the Digital Age Chichester: John Wiley \& Sons, Ltd.; 2006. p. 175-194.

16. Oxman N. Variable Property Rapid Prototyping. Virtual and Physical Prototyping 2011; 6(1):331.

17. Paterson AM, Bibb RJ, Campbell RI and Bingham GA. Comparison of Additive Manufacturing Systems for the Design and Fabrication of Customised Wrist Splints. Rapid Prototyping Journal 2014; 21(3):.

18. Evill J. Cortex. 2013; Available at: http://jakevilldesign.dunked.com/cortex. Accessed 01 August, 3013.

19. Carmichael J. We'd Happily Break Our Wrist For This 3-D Printed Splint. 2013; Available at: http://www.popsci.com/technology/article/2013-08/intricate-3-d-printed-exoskeletonsplints\#comments. Accessed 15 March 2014, 2014.

20. Karasahin D. Osteoid Medical cast, attachable bone stimulator by Deniz Karasahin. 2014; Available at: https://www.adesignaward.com/design.php?ID=34151. Accessed 25 March, 2014.

21. Fraunhofer IPA. Fraunhofer Institute for Manufacturing Engineering and Automation. 2012; Available at: http://www.ipa.fraunhofer.de/index.php?L=2. Accessed 10 December, 2012.

22. Grzesiak A. Fraunhofer Additive Manufacturing Alliance - Highlights, current RTD activities and strategic topics. In: Fraunhofer (ed). Proceedings of the Additive Manufacturing International Conference, July 08, 2010.Loughborough University; 2010.

23. Bibb R, Eggbeer D and Evans P. Rapid Prototyping technologies in soft tissue facial prosthetics: current state of the art. Rapid Prototyping Journal 2010; 16(2):130-137.

24. Fried S, inventor. AnonymousSplint and or Method of Making Same. . 2007. 
25. Rogers B, Stephens S, Gitter A, Bosker G and Crawford R. Double-Wall, Transtibial Prosthetic Socket Fabricated Using Selective Laser Sintering: A Case Study. Journal of Prosthetics and Orthotics 2000; 12(3):97-100.

26. Pallari JHP, Dalgarno KW and Woodburn J. Mass Customisation of Foot Orthoses for Rheumatoid Arthritis Using Selective Laser Sintering. IEEE Transactions on Biomedical Engineering 2010; 57(7):1750-1756.

27. R.J. Bibb. Lattice within splints. Drawing. July 22. 2009.

28. Paterson AM, Bibb RJ and Campbell RI. Evaluation of a refined three-dimensional Computer Aided Design workflow for upper extremity splint design to support Additive Manufacture. In: Bocking C and Rennie AEW (eds). Thirteenth Conference on Rapid Design, Prototyping and Manufacturing, 22 June 2012.CRDM Ltd, High Wycombe.; 2012.

29. Lohman H. Wrist Immobilisation splints. In: Coppard BM, Lohman H (eds.) Introduction to splinting: A clinical reasoning \& problem-solving approach. Second ed. St Louis, MO.: Mosby, Inc.; 2001. p. 139-184.

30. Austin NM. Process of Splinting. In: Jacobs M, Austin NM (eds.) Splinting the Hand and Upper Extremity: Principles and Process Baltimore: Lippincott Williams \& Wilkins; 2003. p. 88-99.

31. Jacobs M, Austin N. Splint Fabrication. In: Jacobs M, Austin N (eds.) Splinting the Hand and Upper Extremity: Principles and Process Baltimore: Lippincott Williams \& Wilkins; 2003. p. 98157.

32. Paterson AM. Digitisation of the Splinting Process: Exploration and Evaluation of a Computer Aided Design approach to support Additive Manufacture. PhD Thesis. Loughborough University; 2013.

33. Paterson AM, Bibb RJ and Campbell RI. Evaluation of a digitised splinting approach with multiple-material functionality using Additive Manufacturing technologies. In: Bourell D, Crawford RH, Seepersad CC, Beaman JJ and Marcus H (eds). Proceedings of the 23rd Annual International Solid Freeform Fabrication Symposium - An Additive Manufacturing Conference, 6-8 August 2012.University of Texas at Austin; 2012. 